\title{
Laparoscopic partial nephrectomy: state of the art review
}

\author{
Izak Faiena \\ Christopher Sejong Han \\ Ephrem O Olweny \\ Division of Urology, Department \\ of Surgery, Rutgers-Robert Wood \\ Johnson Medical School, New \\ Brunswick, NJ, USA
}

This article was published in the following Dove Press journal:

Open Access Surgery

27 May 2014

Number of times this article has been viewed

Introduction: The surgical management of small renal masses $(<4 \mathrm{~cm})$ has greatly evolved over the last few decades, with the paradigm shifting from radical to partial nephrectomy. Laparoscopic partial nephrectomy (LPN) is increasingly utilized, and has achieved similar outcomes to open partial nephrectomy with decreased patient morbidity in experienced hands. The aim of this review was to examine the current status and future direction of LPN.

Materials and methods: We performed a nonsystematic review of the literature using a free-text protocol in the PubMed database, using the terms "laparoscopic partial nephrectomy", "robotassisted partial nephrectomy", "robotic partial nephrectomy", and "laparoscopic partial nephrectomy oncologic and functional outcomes". Only English language articles were selected.

Evidence synthesis: Our search results yielded 1,136. Three authors reviewed the results, and articles with information on patient and tumor selection, surgical techniques, and oncologic and functional outcomes were included. With regard to outcomes, only series with the largest cohorts and longest follow-up were selected.

Conclusion: LPN has evolved rapidly over the past 2 decades, and advances in technique as well as innovations in surgical technologies have facilitated its increased adoption in urologic practice. However, limitations remain, such as inadequacy of techniques to achieve cold ischemia laparoscopically, high technical demands of intracorporeal suturing, and limited ability to assess surgical anatomy beyond the field of view. These comprise goals of research aimed at improving future surgical precision and outcomes, while further decreasing the invasiveness of LPN.

Keywords: nephrectomy, robotics, kidney

\section{Introduction}

Kidney cancer is the third most common genitourinary malignancy and the third leading cause of genitourinary cancer-related mortality, with an estimated 65,150 new cases and 13,680 deaths in 2013 in the United States. ${ }^{1}$ Historically, kidney cancer presented as a large, symptomatic, and frequently invasive or metastatic renal mass. However, over the past 3 decades there has been a notable evolution in the presentation and treatment of kidney cancer, particularly of small renal masses (SRM) defined as those masses less than $4 \mathrm{~cm}$ in size. Examining the Surveillance, Epidemiology and End Results cancer registry from 1983 to 2002, Nguyen et al reported a 52\% increase in the overall rate of kidney cancers diagnosed in the United States, from 7.1 to 10.8 cases per 100,000 , with the greatest increase in SRM. Seventy percent of newly diagnosed renal cancers were clinical stage T1a. ${ }^{2}$ This has largely been attributed to the prevalent use of modern cross-sectional imaging techniques including ultrasonography, computed tomography (CT) and magnetic resonance imaging.

\footnotetext{
Division of Urology, Department of Surgery, Rutgers Robert Wood Johnson Medical School, I Robert Wood Johnson Place, MEB 588B,

New Brunswick, NJ, 0890I, USA

Tel +l 7322357775

Fax +I 7322358018

Email eolweny@gmail.com
}

Correspondence: Ephrem O Olweny submit your manuscript $\mid$ www.dovepress.com

Dovepress

http://dx.doi.org//0.2147/OAS.S40275
Open Access Surgery 2014:7 59-69 
With recent studies demonstrating a strong link between decreased kidney function and increased risk of cardiovascular disease and mortality, ${ }^{3}$ preservation of renal function has become an important consideration in renal oncologic surgery. This has resulted in expansion of the indications of partial nephrectomy (PN) such that it is presently considered the standard of care in the treatment of all SRM. ${ }^{4}$

Advances toward the modern PN began in the 1960s when Poutasse improved the technique by dissection of the segmental blood supply to the level of kidney. Kerr and Klotz introduced renal hypothermia, which helped to minimize renal ischemic damage, thereby permitting longer operations and complicated reconstructions of the kidney in a relatively bloodless field. ${ }^{5}$ The laparoscopic surgical revolution began in the 1970s and achieved a major milestone in 1991 with the demonstration of feasibility of laparoscopic nephrectomy for removal of a tumor-bearing kidney by Clayman et al. ${ }^{6}$ This was the first reported removal of a solid organ using purely laparoscopic techniques. This paved the way for the subsequent development of laparoscopic PN (LPN) first performed by Winfield et al in $1993 .{ }^{7}$ The most significant challenges of early LPN were replication of the sound oncologic outcomes of its open counterpart, as well as its high technical demands. These challenges have been mitigated over time by various innovations in both surgical technique and technology, including incorporation of the robotic surgical platform for LPN as first described by Gettman et al in 2004. ${ }^{8}$

In this review we aim to bring the reader up to date with information regarding new techniques, results of large studies on functional and oncologic outcomes, as well as future direction in this fast evolving field of minimally invasive treatment of small renal masses.

\section{Materials and methods}

We performed a nonsystematic review of the literature using the PubMed database. The PubMed search included only a free-text protocol using the terms "robot-assisted partial nephrectomy", "robotic partial nephrectomy", "laparoscopic partial nephrectomy", and "laparoscopic partial nephrectomy oncologic and functional outcomes" across the title and abstract fields of the records. Search results yielded 1,136 articles, which were reviewed by three authors. Only English language articles were considered. With regards to functional and oncologic outcomes, only articles with the largest cohort and longest follow-up were considered. Articles pertaining to the latest techniques in PN as well as those evaluating functional and oncologic outcomes as compared to open PN (OPN) were also included. Other significant studies cited in the reference lists of the selected papers were also evaluated.

\section{Evidence synthesis and discussion \\ Patient selection}

Similar to OPN, and depending on surgeon comfort level, LPN can be used in patients with SRM in whom nephronsparing surgery is absolutely indicated, such as solitary kidney, renal insufficiency, or those with bilateral renal tumors. These indications have expanded over time to include most elective T1 tumors, as well as more complex tumors, such as T1b, central, hilar, multiple, and/or cystic tumors. Patient selection and preparation for renal surgery in these cases is comparable to that for open surgery. A pertinent history and physical examination are necessary to identify potential issues that could arise during surgery. Prior abdominal, retroperitoneal, or renal surgery is no longer considered a contraindication to laparoscopic surgery. The type and extent of prior abdominal surgery will, however, dictate trocar locations as well as surgical approach taken (transperitoneal versus extraperitoneal). Patient factors such as obesity have been demonstrated to have no impact on perioperative outcomes in the hands of experienced surgeons. However, the incidence of Clavien grade $\geq$ III complications was higher for obese compared to nonobese patients in one study, although low overall. ${ }^{9}$

The use of the RENAL nephrometry score (NS) has aided in providing a reproducible standardized classification system that quantitates the salient anatomy of renal masses. ${ }^{10}$ The nephrometry score is based on five critical and reproducible anatomical features of solid renal masses. It consists of radius ( $\mathrm{R}$; tumor size as maximal diameter), exophytic/endophytic properties of the tumor (E), nearness of tumor to the collecting system or sinus (N), anterior (A)/ posterior $(\mathrm{P})$ descriptor, and the location relative to the polar line (L). The suffix $h$ (hilar) is assigned to tumors that abut the main renal artery or vein. Of the five components, four are scored on a 1-, 2-, or 3-point scale, with the fifth component indicating the anterior or posterior location of the mass relative to the coronal plane of the kidney. This has become a useful tool to help stratify patients into the different modalities of renal extirpation. Canter et al evaluated the relationship between a tumor's NS and the treatment rendered, and found that the higher the complexity of the tumor the more likely it was that the patient received radical nephrectomy (RN). ${ }^{11}$ For low-, moderate-, and high-score tumors, rates of $\mathrm{RN}$ were $6 \%, 23 \%, 66 \%$, respectively. Other studies have found that the RENAL NS is a comprehensive and 
reproducible tool that may aid surgeons in communicating tumor characteristics effectively. Interobserver correlation is high, rendering it a high fidelity assessment tool. ${ }^{12}$ Similar to Canter et al, other groups have shown that RENAL NS predicted surgeon preference for selection of RN versus PN in retrospective analyses. ${ }^{13}$

Other standardized scoring systems include the preoperative aspects and dimensions used for anatomic (PADUA) classification and centrality (c)-index scores. In one study, all three scoring systems demonstrated strong interobserver reliability and correlation with some perioperative outcomes such as warm ischemia time (WIT). ${ }^{14}$

\section{Surgical techniques}

Laparoscopic surgical approaches to the kidney during PN presently include transperitoneal, retroperitoneal, handassisted, robotic, laparoendoscopic single-site surgery (LESS), and natural orifice transluminal endoscopic surgery (NOTES). With each approach, a pneumoperitoneum is created to increase the intra-abdominal working space. LESS and NOTES represent the most recent innovations in laparoscopic renal surgery and are aimed at further reduction in surgical morbidity, partly by limiting the size and number of abdominal trocars. In LESS, multiple laparoscopic instruments are used through a single abdominal incision, with the occasional use of an accessory instrument to facilitate triangulation. In NOTES, endoscopic intervention through natural orifices aims at eliminating abdominal incisions altogether. Pending further technological developments and evaluation in preclinical and clinical settings, LESS and NOTES presently have very limited clinical applicability, with NOTES considered primarily experimental.

\section{Transperitoneal LPN}

The transperitoneal approach was the first described technique for $\mathrm{LPN}^{7}$ and it remains the most widely used approach used today. It has undergone significant evolution and technical refinements since inception. Major challenges during the initial experience included minimizing WIT, maintenance of hemostasis, and achieving satisfactory repair of the collecting system. In the initial experience with transperitoneal LPN, procedures were done for benign disease and renal ischemia was not obtained. Hemostasis was achieved using the argon beam coagulator. ${ }^{15} \mathrm{~A}$ variety of energy-based technologies and tourniquet devices for simultaneous sealing of blood vessels and the renal collecting system were subsequently employed - monopolar shears, ultrasonic shears, microwave tissue coagulators, electrosurgical snares, laser devices, and radiofrequency-assisted resection are some examples. ${ }^{16}$ In 2002, Gill et al described duplication of OPN techniques during LPN. ${ }^{17}$ En bloc hilar control was obtained using a laparoscopic Satinsky clamp during transperitoneal LPN (Figure 1), and laparoscopic bulldog clamps during retroperitoneal LPN. Tumor resection was done sharply with or without the adjunct use of electrocautery. Renorrhaphy following tumor excision was performed by intracorporeal suturing using absorbable polyglactin 2-0 sized sutures. ${ }^{17}$ These techniques for both transperitoneal and retroperitoneal LPN, with subsequent modifications, have become the primary methods by which LPN is performed today.

Tumor excision during LPN is conventionally performed using laparoscopic scissors with or without electrocautery. However, other techniques have been described; notably, the use of a variety of lasers with or without hilar clamping. ${ }^{18,19}$ Loertzer et $\mathrm{al}^{20}$ described the use of the $2.0 \mu \mathrm{m}$ continuous wave laser (RevoLix ${ }^{\mathrm{TM}}$; LISA Laser USA, Pleasanton, CA, USA), which is a diode pumped solid-state laser with an emitting wavelength of $2,013 \mathrm{~nm}$. The laser penetrates tissue to a depth of about $0.5 \mathrm{~mm}$. In this prospective cohort, eleven patients underwent unclamped LPN using the RevoLix ${ }^{\mathrm{TM}}$ laser for resection. All patients had exophytic tumors with RENAL NS less than 9. No significant bleeding requiring other hemostatic measures was encountered. All malignant tumors were resected with negative margins.

Intracorporeal suturing remains one of the most technically demanding challenges of LPN, particularly under the time constraint of warm ischemia. Various authors have described technique modifications to improve efficiency with this step. Orvieto et al described use of anchoring Lapra-Ty ${ }^{\circledR}$ clips (Ethicon Endosurgery, Johnson \& Johnson,

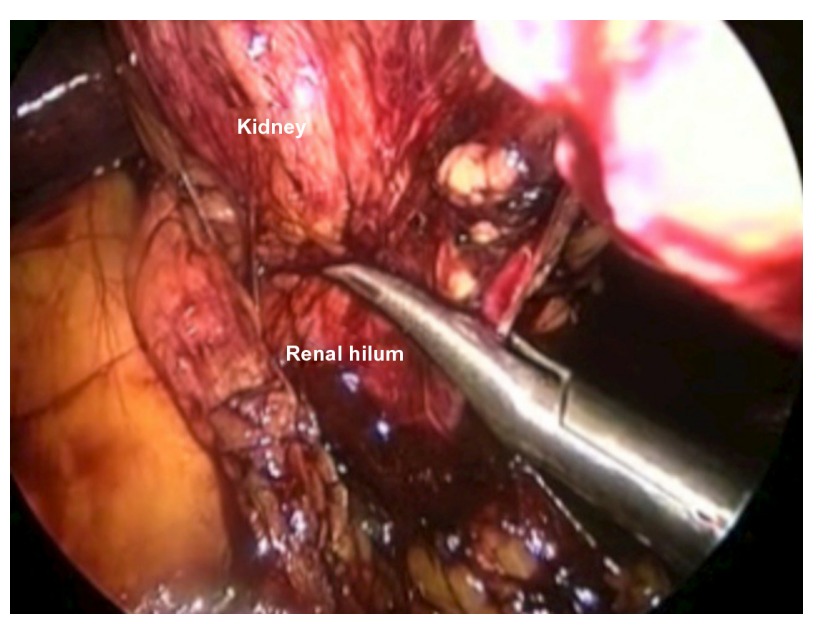

Figure I Laparoscopic partial nephrectomy; en bloc hilar clamping using laparoscopic Satinsky clamp. 
New Brunswick, NJ, USA) at the suture ends to eliminate knot tying. ${ }^{21}$ Taut suture line tension achieved with this approach was thought to possibly be useful in preventing postoperative pseudoaneurysms and/or urine leaks. Sliding clip renorrhaphy is another innovation, first described by Benway et al. ${ }^{22}$ In this technique, a Hem-o-lock clip (Teleflex Medical, Research Triangle Park, NC, USA) is loaded on either end of the renorrhaphy sutures that are placed across the resection bed through the renal capsule. The clips are then slid onto the capsule to achieve capsular compression. The clip spreads out the forces applied to the surface of the renal capsule, avoiding renal parenchymal shearing. Knot tying is eliminated, further improving the suturing efficiency. The amount of tension applied is judged by the dimpling of the renal capsule. ${ }^{23}$ The use of adjunctive biologic hemostatic/sealant agents and/or oxidized cellulose bolsters is optional.

Recent innovations in suture design include the introduction of self-retaining barbed suture (SRBS), originally developed for wound closure during plastic surgery procedures. ${ }^{24}$ The two kinds of SRBS include the unidirectional V-Loc ${ }^{\mathrm{TM}}$ (Covidien, Mansfield, MA, USA) and the bi-directional Quill ${ }^{\mathrm{TM}}$ suture (Angiotech Pharmaceuticals, Inc., Vancouver, BC, Canada). These sutures have anchoring barbs that help maintain suture line tension, thus improving suturing efficiency by eliminating the need for frequent tensioning. In animal studies, the Quill ${ }^{\mathrm{TM}}$ suture (Angiotech, Vancouver, BC, Canada) was found to be as effective, efficient, and safe as conventional suturing during LPN. ${ }^{25}$ Similarly, in clinical studies, the use of SRBS during LPN has been demonstrated to decrease WIT and perioperative complications. ${ }^{26-28}$

\section{Retroperitoneal LPN}

Although transperitoneal LPN is the most common and preferred technique for most renal tumors, some surgeons utilize the retroperitoneal approach for select posteriorly located tumors. This retroperitoneal approach mimics open surgery in that the peritoneal cavity is avoided. A potential space is created to visualize the surgical field. After entry into the retroperitoneum and establishment of a working space, the kidney is lifted anteriorly off the psoas muscle to allow visualization and dissection of the renal hilum and placement of bulldog clamps. Tumor localization and excision, hemostasis, collecting system repair, and renorrhaphy are performed as in the transperitoneal approach. Several of the recent surgical and technological innovations described for transperitoneal LPN have been applied to retroperitoneal LPN as well.
In a comparison of 32 retroperitoneal with 19 transperitoneal LPNs, choice of approach was based on the tumor location. ${ }^{29} \mathrm{Ng}$ et $\mathrm{l}^{30}$ compared 100 transperitoneal with 63 retroperitoneal LPNs and found that blood loss, perioperative complications, postoperative serum creatinine, analgesic requirements, and histological outcomes were comparable in the two groups. In a recent meta-analysis, Fan et al found that retroperitoneal LPN had a shorter operating time and was equally as safe as transperitoneal LPN in appropriately selected patients, particularly those with posteriorly located renal tumors. ${ }^{31}$ However, the authors concluded that these results must be interpreted with caution as all of the included studies were observational and were conducted with varying protocols at different levels of surgical expertise. Furthermore, the studies were mostly conducted at major institutions and, therefore, may not reflect patient populations in the community.

The major drawbacks of the retroperitoneal approach are the limited working space and more subtle anatomic landmarks. The smaller working space limits the distance between trocars, potentially leading to awkward hand positioning and ergonomic difficulties.

\section{Hand-assisted LPN}

Hand-assisted LPN (Figure 2) offers the surgeon the benefits of preserved tactile sensation, ability to perform blunt dissection, and improved control of intraoperative complications such as hemorrhage. It maintains the benefits of laparoscopic surgery for the patient while providing the surgeon some of the advantages of open surgery. In early experiences with the technique, despite the ability to perform parenchymal compression, hilar clamping was advocated by some authors as significant hemorrhage was

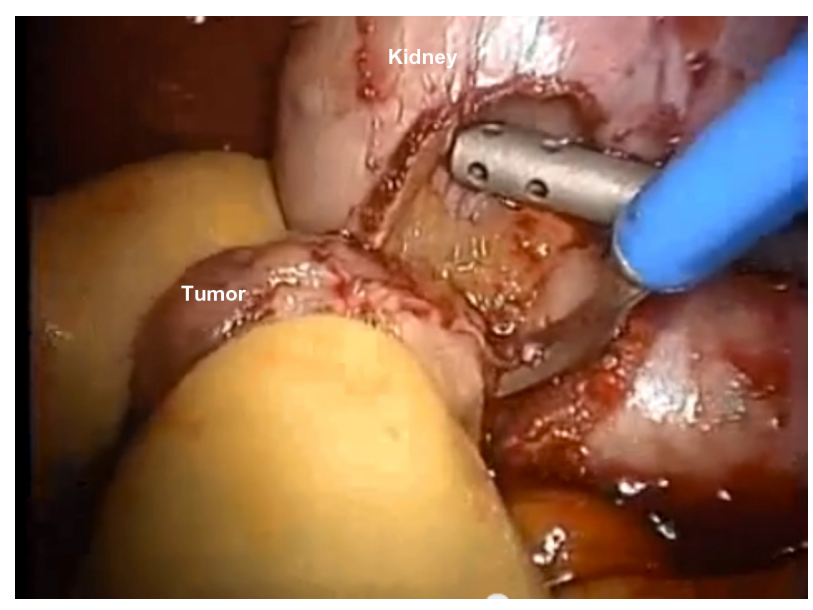

Figure 2 Hand-assisted laparoscopic partial nephrectomy. 
still observed in a few cases, primarily involving central lesions. ${ }^{32}$ However, in more recent experience, hand-assisted LPN has been shown to enable off-clamp PN, even for primarily endophytic lesions, with acceptably low complication rates. ${ }^{33}$

\section{Robotic-assisted laparoscopic PN}

Robotic-assisted LPN (RALPN) was first introduced in $2004^{8}$ and is rapidly becoming the technique of choice for the surgical treatment of SRM. ${ }^{34}$ The robotic surgical platform incorporates articulating EndoWrist ${ }^{\circledR}$, (Intuitive Surgical, Sunnyvale, CA, USA) instruments that are controlled through a computer interface, allowing degrees of maneuverability not achievable with conventional laparoscopic instruments. Additionally, visibility is enhanced through the 3D highdefinition camera-lens system (Figure 3).

A decreased learning curve for RALPN compared with conventional LPN has been reported. ${ }^{35,36}$ Furthermore, surgeons highly experienced with laparoscopic renal surgery have adopted RALPN for use with moderately and highly complex renal masses with excellent outcomes. ${ }^{37,38}$ The robotic platform has also been used in retroperitoneal LPN with a demonstrated shorter learning curve and similar functional and oncological outcomes to the traditional retroperitoneoscopic LPN. ${ }^{39}$

\section{LESS/NOTES PN}

One of the earliest experiences with LESS PN was reported by Aron et al in 2009. ${ }^{40}$ They described their technique in four patients with a median tumor size of $3 \mathrm{~cm}$ (range from 1 to $5.9 \mathrm{~cm}$ ). They used a multichannel umbilical R-port (Advanced Surgical Concepts Ltd, Co, Wicklow, Ireland) and an accessory $2 \mathrm{~mm}$ instrument to aid tissue retraction

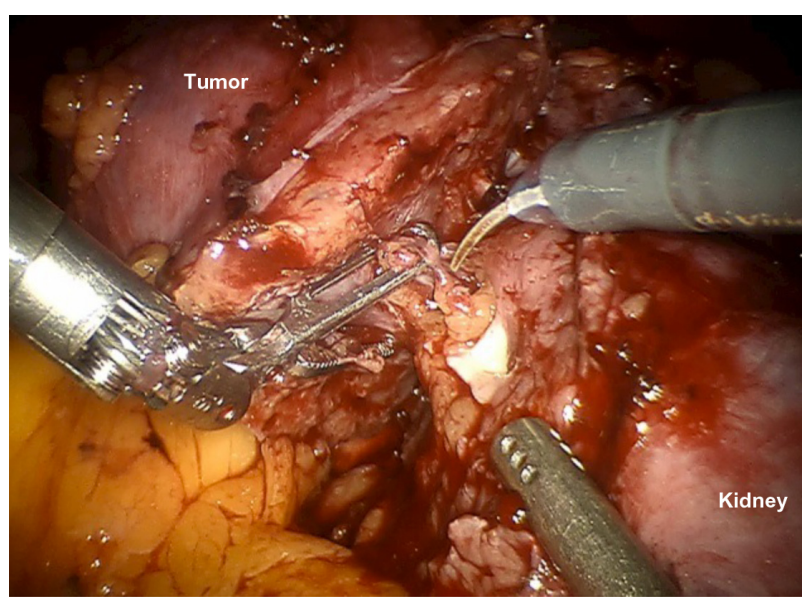

Figure 3 Robotic-assisted laparoscopic partial nephrectomy. in all cases. Conventional laparoscopic and/or articulating instruments as indicated were used for tissue dissection. Median operating time was 270 minutes, and median blood loss was $150 \mathrm{~mL}$. Median WIT was 20 (11-29) minutes and median hospital stay was 3 days. One patient developed postoperative hemorrhage and pulmonary embolism. ${ }^{40}$

The da Vinci-S robotic surgical system (Intuitive Surgical, Sunnyvale, CA, USA) has also been adapted for use in LESS PN. ${ }^{41}$ However, a recent study comparing 89 patients who had undergone multiport robotic PN (RPN) with 78 patients with robotic laparoendoscopic single site PN (R-LESS) found that patients who had undergone conventional RPN had superior outcomes as compared to R-LESS PN, with regard to the accomplishment of negative margins and reduced WIT and surgical complications. ${ }^{42}$ NOTES PN has not been performed clinically to date.

\section{Outcomes of LPN}

\section{Functional outcomes}

The efficacy and safety of PN have been surveyed with functional and oncological outcomes. OPN, the current gold standard, has been shown to yield equivalent oncological outcomes and superior functional outcomes when compared to RN. ${ }^{43,44}$ With the higher than expected prevalence of undetected chronic kidney disease (CKD) in patients undergoing $\mathrm{PN}$, preservation of as much renal function as possible is a crucial consideration when performing PN. . $^{4,46}$

Various studies have compared renal functional outcomes for minimally invasive (laparoscopic and robotic) PN to those for OPN (Table 1). In one of the largest retrospective studies including approximately 1,800 consecutive patients who underwent open $(n=1,028)$ or laparoscopic $(n=771) P N$, similar 3-month postoperative renal functional outcomes were observed. ${ }^{46}$ Renal function was preserved in $99.6 \%$ and $97.9 \%$ of patients undergoing OPN and LPN, respectively. However, LPN was associated with longer ischemia times and higher rates of postoperative complications. ${ }^{46}$ Lee et al similarly reported comparable postoperative functional outcomes between OPN and RPN. ${ }^{47}$ No significant differences between the groups in postoperative estimated glomerular filtration rate (eGFR) or change in postoperative eGFR at 1 month were observed. ${ }^{47}$ In a long-term study, Springer et al found no difference between LPN and OPN in postoperative eGFR at 5 years. ${ }^{48}$ Similarly, in a study of RPN with intermediate-term follow-up, only an $8 \%$ mean decrease in postoperative eGFR was observed at a mean follow-up of 3 years. ${ }^{49}$ Longer-term comparisons of functional outcomes for RPN with other surgical approaches are currently lacking. 
Table I Comparison of functional outcomes for minimally invasive versus open partial nephrectomy

\begin{tabular}{|c|c|c|c|c|c|c|c|}
\hline & Groups & $\begin{array}{l}\text { Cohort } \\
\text { size }\end{array}$ & $\begin{array}{l}\text { Follow-up } \\
\text { months } \\
\text { (mean/median) }\end{array}$ & $\begin{array}{l}\text { Mean } \\
\text { tumor size }\end{array}$ & $\begin{array}{l}\text { Mean WIT } \\
\text { (minutes) }\end{array}$ & $\begin{array}{l}\Delta \text { in eGFR } \\
\left(\mathrm{mL} / \mathrm{min} / 1.72 \mathrm{~cm}^{2}\right)\end{array}$ & $\begin{array}{l}\Delta \text { in serum } \mathrm{Cr} \\
(\mathrm{mg} / \mathrm{dL})\end{array}$ \\
\hline \multirow[t]{2}{*}{ Gill et $\mathrm{al}^{46}$} & OPN & 1,029 & $33.6 / 14.4$ & $3.5 \mathrm{~cm}$ & $20.1^{*}$ & $\mathrm{n} / \mathrm{a}$ & 0.17 \\
\hline & LPN & 771 & & $2.7 \mathrm{~cm}$ & $30.7^{*}$ & $\mathrm{n} / \mathrm{a}$ & 0.17 \\
\hline \multirow[t]{2}{*}{ Springer et al ${ }^{48}$} & OPN & 170 & $54.3 / 45.7$ & $2.9 \mathrm{~cm}$ & $14.4^{*}$ & -9.9 & $\mathrm{n} / \mathrm{a}$ \\
\hline & LPN & 170 & & $2.8 \mathrm{~cm}$ & $11.7^{*}$ & -10.4 & $\mathrm{n} / \mathrm{a}$ \\
\hline \multirow[t]{2}{*}{ Lane et $\mathrm{al}^{77}$} & OPN & 916 & $93.6 / 79.2$ & $3.5 \mathrm{~cm}$ & $\mathrm{n} / \mathrm{a}$ & -12.0 & 0.2 \\
\hline & LPN & 625 & & $2.6 \mathrm{~cm}$ & $\mathrm{n} / \mathrm{a}$ & -13.0 & 0.2 \\
\hline \multirow[t]{2}{*}{ Lee et $\mathrm{a}^{147}$} & OPN & 234 & $1 / 1$ & $2.58 \mathrm{~cm}$ & $18.14 *$ & -5.25 & 0.07 \\
\hline & RPN & 69 & & $2.37 \mathrm{~cm}$ & $22.99 *$ & -6.11 & 0.06 \\
\hline Khalifeh et $\mathrm{al}^{49}$ & RPN & 134 & $36 /-$ & $3.0 \mathrm{~cm}$ & 17.9 & -7.4 & 0.08 \\
\hline
\end{tabular}

Note: *Statistically significant difference $(P<0.05)$.

Abbreviations: $\Delta$, change; Cr, creatinine; eGFR, estimated glomerular filtration rate; LPN, laparoscopic partial nephrectomy; n/a, not applicable; OPN, open partial nephrectomy; RPN, robotic partial nephrectomy; WIT, warm ischemia time.

Retrospective studies have also shown that postoperative renal function after PN is predicted by several risk factors including age, sex, preoperative renal function, and percent of renal parenchyma preserved. ${ }^{50-54}$ These parameters have been utilized in a prognostic nomogram developed from the Memorial Sloan-Kettering PN database,${ }^{50}$ which was shown to have a predictive value of 0.835 for determining the 7 -year probability of developing postoperative renal insufficiency. It is currently being utilized in counseling patients prior to intervention.

\section{A note on warm ischemia during LPN}

Warm ischemia is considered a modifiable risk factor that has a potential impact on postoperative renal functional outcomes after LPN. It remains a primary drawback to LPN as reliable and easily reproducible techniques to achieve adequate intrarenal cooling in the clinical setting have not been developed to date. Several authors have described techniques to achieve renal cooling during LPN, but many of the approaches described to date, such as laparoscopic ice slush, intra-arterial cold saline perfusion, and retrograde endoscopic cold saline perfusion, remain challenging or cumbersome to implement and are not widely used clinically. ${ }^{5-57}$ The studies with these renal hypothermia techniques during LPN, however, have demonstrated comparable functional outcomes to those studies with acceptable WIT. A retrospective study with 71 patients with renal hypothermia induced by ice-slush cooling demonstrated comparable median postoperative eGFR decrease of 8.9 $\mathrm{mL} / \mathrm{min} / 1.73 \mathrm{~m}^{2} 6$ months postoperatively with median cold ischemic time of 57 minutes (including initial 15 minutes of hypothermia), which is substantially longer than that of other warm ischemic series. ${ }^{58}$ Other studies with renal hypothermia induced by ice-cold saline perfusion also reported acceptable decrease in eGFR and split renal function 2-3 months postoperatively (3.2-7.2 $\mathrm{mL} / \mathrm{min} / 1.73 \mathrm{~m}^{2}$ and $5.3 \%$, respectively) with median of 35-52 minutes of cold ischemia..$^{59,60}$ Schoeppler et al studied the use of a gel-like ice, Freka-Gelice (Fresenius Kabi, Würzburg, Germany), for renal cooling in an in vitro study. ${ }^{61}$ Freka-Gelice is a liquid at room temperature, and turns into a deformable gel that can be delivered through a laparoscopic trocar below $-2^{\circ} \mathrm{C}$. It is nontoxic and warms back into a liquid at room temperature, enabling easy removal. Kidneys were cooled to temperatures comparable to that which was achievable with crushed ice using the gel. Pending further studies, this gel could prove useful in achieving renal cooling during LPN in the clinical setting.

Given the limitations with achieving renal cooling during LPN, several techniques to minimize or eliminate warm ischemia have been proposed, including early unclamping, on-demand clamping, clamp-less nephron sparing surgery with controlled hypotension, super-selective segmental arterial clamping, and super-selective arterial embolization. ${ }^{62-65}$ The safe recommended threshold for WIT is traditionally considered to be 30 minutes; however, some have shown that WIT of less than 20 minutes has no clinically relevant adverse outcomes. ${ }^{66}$ Multiple retrospective studies have examined the impact of warm ischemia on postoperative renal function, often with conflicting results. A recent large retrospective multiinstitutional study examined ischemia time during OPN in 660 patients with solitary kidneys, and found that, at 3 months postoperatively, there was no significant difference in the rate of median eGFR decrease for cold versus warm ischemia (21\% versus $22 \%$, respectively, $P=0.7) .{ }^{53}$ However, median cold ischemia times were significantly longer ( 45 versus 22 minutes, respectively, $P<0.001)$. On multivariable analysis excluding percentage of kidney parenchyma preserved, increasing age, 
larger tumor size, lower preoperative eGFR, and longer ischemia time were associated with decreased postoperative eGFR $\left(P<0.05\right.$ for each).$^{53}$ However, when percentage of kidney parenchyma preserved was incorporated into the analysis, this parameter, as well as preoperative glomerular filtration rate, proved to be the primary determinant of postoperative renal function, while duration of ischemia was no longer statistically significant. ${ }^{53}$ Another retrospective analysis of over 1,100 patients included over 400 patients who underwent LPN with warm ischemia duration less than 30 minutes. This cohort also included 58 patients who underwent surgery without ischemia ([PN0] $60 \%$ of these underwent LPN). These PN0 patients had smaller tumors with greater percentages of kidney parenchyma preserved, and had a smaller relative decrease in postoperative renal function. Importantly, the incidence of decline to stage III CKD was $9.4 \%$ in PN0 patients, compared with $14.7 \%$ in the WIT less than 30 minutes cohort and $12.8 \%$ in the cold ischemia cohort. Although this analysis concluded that ischemia type (no ischemia versus limited warm ischemia versus cold ischemia) did not predict postoperative renal function, the authors still posited that minimizing WIT was important in patients at highest risk for CKD upstaging. Further evidence from Thompson et $\mathrm{a}^{67}$ showed that duration of warm ischemia, when viewed as a continuous variable, correlated with acute renal failure and development of eGFR less than $15 \mathrm{~mL} / \mathrm{min} / 1.73 \mathrm{~m}^{2}$, even after controlling for nonmodifiable factors (baseline eGFR and tumor size). The authors concluded that every minute of warm ischemia imparted additional risk of significant postoperative renal dysfunction. ${ }^{67}$

Most recently, techniques of unclamped zero-ischemia PN have yielded promising functional outcomes. Retrospective studies have shown that unclamped $\mathrm{PN}$ in patients with two normal kidneys results in a lesser degree of postoperative eGFR decline at 1 year. ${ }^{68,69}$ Other techniques include segmental ${ }^{70}$ and subsegmental artery dissection and microclamping ${ }^{71,72}$ whereby, after hilar exposure, segmental and subsegmental arteries are dissected under laparoscopic Doppler ultrasound guidance. The peritumoral arteries identified are then superselectively clamped using a micro-bulldog clamp. Several authors have demonstrated that vascular microdissection and occlusion results in minimal postoperative eGFR change, even when used for high-complexity tumors. ${ }^{72,73}$ Techniques to produce regional ischemia in LPN have also been introduced using Rumel tourniquet or Satinsky clamp applied proximal to the line of resection. ${ }^{7,74}$ More recently, successful use of the Nussbaum clamp modified for laparoscopic application to maintain constant pressure without the risk of device slippage has been demonstrated with exophytic tumors. ${ }^{75}$ In Simon et al's initial study with three patients, ${ }^{75}$ resection in a bloodless field is achieved without the need for renal pedicle dissection. After the total clamping time ranging from 23 to 38 minutes, postoperative creatinine levels remain unchanged in their study.

Only one prospective clinical study to date has investigated the tolerance of the human kidney to ischemia. ${ }^{76}$ In this study, 40 patients undergoing OPN had renal biopsies obtained before, during, and after ischemia for electron microscopic analysis of ultrastructural changes. Serum creatinine, cystatin $\mathrm{C}$, and other biomarkers of renal injury were compared before and after ischemia. Median duration of ischemia in patients undergoing warm ischemia was 32.3 (15-53) minutes, and those undergoing cold ischemia was 48 (30-61) minutes. No differences in any of the outcomes analyzed were found between cold and warm ischemia, and thus patient data were pooled for the final analysis. No significant changes from baseline in postoperative renal function or ultrastructural change were found, despite ischemia durations of up to 60 minutes. Other biomarkers were only mildly elevated, but this did not correlate with renal function or ischemia duration. The authors concluded that the human kidney is tolerant of ischemia durations of up to 60 minutes with minimal impact on renal function or structural change. Furthermore, these findings were similar for warm versus cold ischemia. ${ }^{76}$

\section{Oncologic outcomes}

Long-term oncological outcomes for LPN have recently been reported and compared to those for OPN (Table 2). Lane et al reported 10-year outcomes in patients with a solitary $\mathrm{T} 1$ renal tumor who underwent either open $(n=916)$ or laparoscopic ( $n=625)$ PN. Patients were followed for a minimum of 5 years posttreatment (median 6.6 years for LPN and 7.8 years for OPN). ${ }^{77}$ Metastasis-free survival was $96.9 \%$ versus $92.3 \%$ in patients treated with LPN and OPN, respectively. ${ }^{77}$ On multivariable analysis, no association between the metastasis-free survival and surgical approach was found. Similarly, Springer et al reported comparable 5-year overall survival $(94 \%$ versus 91\%) and cancer-specific survival (92\% versus $88 \%$ ) in patients undergoing LPN versus OPN, respectively. ${ }^{48}$

In a study of 134 patients treated with RPN and followed for a minimum of 2 years, Khalifeh et al reported actuarial 5 -year overall survival and cancer-specific survival rates of $90 \%$ and $99 \%$, respectively. ${ }^{49}$ Gupta et al similarly reported no local or metastatic recurrences following RPN at a median follow-up of 22 months. ${ }^{78}$ Despite these early promising data for RPN, some studies have also shown a higher, albeit statistically insignificant, occurrence of positive surgical margins 
Table 2 Comparison of oncologic outcomes for minimally invasive versus open partial nephrectomy

\begin{tabular}{|c|c|c|c|c|c|c|c|c|}
\hline & Groups & $\begin{array}{l}\text { Cohort } \\
\text { size }\end{array}$ & $\begin{array}{l}\text { Follow-up } \\
\text { months } \\
\text { (mean/median) }\end{array}$ & $\begin{array}{l}\text { Mean } \\
\text { tumor size }\end{array}$ & $\begin{array}{l}\text { PSM } \\
\text { rate }\end{array}$ & os & css & RFS \\
\hline Gill et $\mathrm{al}^{46}$ & OPN & 676 & $33.6 / 14.4$ & $3.5 \mathrm{~cm}$ & $1.26 \%$ & $\mathrm{n} / \mathrm{a}$ & $99.2 \%$ (3-year CSS) & $\mathrm{n} / \mathrm{a}$ \\
\hline (subgroup analysis) & LPN & 514 & & $2.7 \mathrm{~cm}$ & $2.85 \%$ & $\mathrm{n} / \mathrm{a}$ & $99.3 \%$ (3-year CSS) & $\mathrm{n} / \mathrm{a}$ \\
\hline \multirow[t]{2}{*}{ Springer et $\mathrm{al}^{48}$} & OPN & 170 & $54.3 / 45.7$ & $2.9 \mathrm{~cm}$ & $1.7 \%$ & $92 \%$ (5-year OS) & 88\% (5-year CSS) & $\mathrm{n} / \mathrm{a}$ \\
\hline & LPN & 170 & & $2.8 \mathrm{~cm}$ & $1.2 \%$ & $94 \%$ (5-year OS) & $91 \%$ (5-year CSS) & $\mathrm{n} / \mathrm{a}$ \\
\hline \multirow[t]{2}{*}{ Lane et $\mathrm{a}^{17}$} & OPN & 916 & $93.6 / 79.2$ & $3.5 \mathrm{~cm}$ & $0.3 \%$ & $\mathrm{n} / \mathrm{a}$ & $\mathrm{n} / \mathrm{a}$ & $92.7 \%-97.1 \%$ \\
\hline & LPN & 625 & & $2.6 \mathrm{~cm}$ & $1.0 \%$ & $\mathrm{n} / \mathrm{a}$ & $\mathrm{n} / \mathrm{a}$ & $\begin{array}{l}\text { (5-year RFS) } \\
93.1 \%-97.8 \% \\
\text { (5-year RFS) }\end{array}$ \\
\hline Khalifeh et $\mathrm{al}^{49}$ & RPN & 134 & $36 /-$ & $3.0 \mathrm{~cm}$ & $1.0 \%$ & $90.2 \%$ (5-year OS) & 99\% (5-year CSS) & $\mathrm{n} / \mathrm{a}$ \\
\hline
\end{tabular}

Abbreviations: CSS, cancer-specific survival; LPN, laparoscopic partial nephrectomy; n/a, not applicable; OPN, open partial nephrectomy; OS, overall survival; PSM, positive surgical margin; RFS, recurrence-free survival; RPN, robotic partial nephrectomy.

(PSM) during RPN as compared to LPN (3.9\% versus $0.8 \%$, respectively, $P=0.11) .{ }^{79}$ Early studies had demonstrated an insignificant oncologic effect of PSM with respect to local or metastatic recurrence, ${ }^{80,81}$ but emerging data conflict with these earlier findings ${ }^{82}$ Pending further studies on the oncologic significance of PSM during PN, meticulous and complete surgical resection with close follow-up of patients with known PSM is recommended.

\section{Future directions}

Surgical robotics has greatly enhanced the surgeon's capability to perform more precise and sophisticated minimally invasive surgery, but challenges remain. Currently, surgeons rely on memory of the preoperative imaging of the surgical anatomy, which is combined with surgeon experience and, when available, tactile feedback to facilitate real-time intraoperative decision-making. The ability to achieve visualization beyond the direct field of view, such as of underlying vessels and/or resection margins, would further enhance surgical precision and is a major goal of research in image-guided surgery. Augmented reality is an imageguided system whereby a $3 \mathrm{D}$ reconstructed image of the surgical anatomy is superimposed on the live surgical view. The reconstructed image is generated from preoperative CT or ultrasound imaging studies. This system was first employed in LPN in 2006 for identification of the deep tumor margin. ${ }^{83}$ Using imaging input from 3D CT angiography, it has subsequently been used to visualize the path of the renal arterial tree to aid zero-ischemia PN. ${ }^{84}$ Recently, an augmented reality algorithm that is able to superimpose the $3 \mathrm{D}$ reconstructed image from a $\mathrm{CT}$ scan to the $3 \mathrm{D}$ stereoscopic image from the da Vinci robot was described, and further studies are underway to tailor this for intraoperative use in real time. ${ }^{85}$
Further reducing the invasiveness of laparoscopy is another area of innovation. A miniature robot that is wholly deployable in vivo, with payloads for biopsy, camera, and physiologic sensing, has been developed and evaluated in animal models. ${ }^{86}$ These robots are independently operated from outside the body. With further development, they could enable performance of complex laparoscopic procedures through a single abdominal incision. Several other specialized robotics platforms for LESS and NOTES are also under development, and these could facilitate future clinical implementation of these techniques. ${ }^{87}$

\section{Conclusion}

LPN has undergone significant evolution since the first description of the technique in 1993, and is increasingly used in the treatment of SRM. Functional and oncological outcomes in reported series are similar to those for OPN with acceptably low morbidity rates. Future advances in imageguided surgery and robotic technology are likely to improve surgical precision and outcomes, while further decreasing invasiveness of the technique.

\section{Disclosure}

The authors report no conflicts of interest in this work.

\section{References}

1. Siegel R, Naishadham D, Jemal A. Cancer statistics, 2013. CA Cancer J Clin. 2013;63(1):11-30.

2. Nguyen MM, Gill IS, Ellison LM. The evolving presentation of renal carcinoma in the United States: trends from the Surveillance, Epidemiology, and End Results program. J Urol. 2006; 176(6 Pt 1):2397-2400; discussion 2400.

3. Go AS, Chertow GM, Fan D, McCulloch CE, Hsu CY. Chronic kidney disease and the risks of death, cardiovascular events, and hospitalization. N Engl J Med. 2004;351(13):1296-1305.

4. Campbell SC, Novick AC, Belldegrun A, et al. Guideline for management of the clinical T1 renal mass. J Urol. 2009;182(4):1271-1279. 
5. Herr HW. Surgical management of renal tumors: a historical perspective. Urol Clin North Am. 2008;35(4):543-549.

6. Clayman RV, Kavoussi LR, Soper NJ, et al. Laparoscopic nephrectomy. N Engl J Med. 1991;324(19):1370-1371.

7. Winfield HN, Donovan JF, Godet AS, Clayman RV. Laparoscopic partial nephrectomy: initial case report for benign disease. J Endourol. 1993;7(6):521-526.

8. Gettman MT, Blute ML, Chow GK, Neururer R, Bartsch G, Peschel R. Robotic-assisted laparoscopic partial nephrectomy: technique and initial clinical experience with DaVinci robotic system. Urology. 2004;64(5):914-918

9. Aboumarzouk OM, Stein RJ, Haber GP, Kaouk J, Chlosta PL, Somani BK Laparoscopic partial nephrectomy in obese patients: a systematic review and meta-analysis. BJU Int. 2012;110(9):1244-1250.

10. Kutikov A, Uzzo RG. The RENAL nephrometry score: a comprehensive standardized system for quantitating renal tumor size, location and depth. J Urol. 2009;182(3):844-853.

11. Canter D, Kutikov A, Manley B, et al. Utility of the RENAL nephrometry scoring system in objectifying treatment decision-making of the enhancing renal mass. Urology. 2011;78(5):1089-1094.

12. Montag S, Waingankar N, Sadek MA, Rais-Bahrami S, Kavoussi LR, Vira MA. Reproducibility and fidelity of the RENAL nephrometry score. J Endourol. 2011;25(12):1925-1928.

13. Rosevear HM, Gellhaus PT, Lightfoot AJ, Kresowik TP, Joudi FN, Tracy CR. Utility of the RENAL nephrometry scoring system in the real world: predicting surgeon operative preference and complication risk. BJU Int. 2012;109(5):700-705.

14. Okhunov Z, Rais-Bahrami S, George AK, et al. The comparison of three renal tumor scoring systems: C-Index, PADUA, and RENAL nephrometry scores. J Endourol. 2011;25(12):1921-1924.

15. Winfield HN, Donovan JF, Lund GO, et al. Laparoscopic partial nephrectomy: initial experience and comparison to the open surgical approach. J Urol. 1995;153(5):1409-1414.

16. Ogan K, Cadeddu JA. Minimally invasive management of the small renal tumor: review of laparoscopic partial nephrectomy and ablative techniques. J Endourol. 2002;16(9):635-643.

17. Gill IS, Desai MM, Kaouk JH, et al. Laparoscopic partial nephrectomy for renal tumor: duplicating open surgical techniques. $J$ Urol 2002;167(2 Pt 1):469-476; discussion 475-466.

18. Lotan Y, Gettman MT, Ogan K, Baker LA, Cadeddu JA. Clinical use of the holmium: YAG laser in laparoscopic partial nephrectomy. J Endourol. 2002;16(5):289-292.

19. Khoder WY, Sroka R, Hennig G, et al. The 1,318-nm diode laser supported partial nephrectomy in laparoscopic and open surgery: preliminary results of a prospective feasibility study. Lasers Med Sci. 2011;26(5):689-697.

20. Loertzer H, Strauß A, Ringert RH, Schneider P. Laser-supported partial laparoscopic nephrectomy for renal cell carcinoma without ischaemia time. BMC Urol. 2013;13:31.

21. Orvieto MA, Chien GW, Laven B, Rapp DE, Sokoloff MH, Shalhav AL. Eliminating knot tying during warm ischemia time for laparoscopic partial nephrectomy. J Urol. 2004;172(6 Pt 1):2292-2295.

22. Benway BM, Wang AJ, Cabello JM, Bhayani SB. Robotic partial nephrectomy with sliding-clip renorrhaphy: technique and outcomes. Eur Urol. 2009;55(3):592-599.

23. Wang L, Lee BR. Robotic partial nephrectomy: current technique and outcomes. Int J Urol. 2013;20(9):848-859.

24. Murtha AP, Kaplan AL, Paglia MJ, Mills BB, Feldstein ML, Ruff GL. Evaluation of a novel technique for wound closure using a barbed suture. Plast Reconstr Surg. 2006;117(6):1769-1780.

25. Shikanov S, Wille M, Large M, et al. Knotless closure of the collecting system and renal parenchyma with a novel barbed suture during laparoscopic porcine partial nephrectomy. J Endourol. 2009;23(7): $1157-1160$.

26. Olweny EO, Park SK, Seideman CA, Best SL, Cadeddu JA. Selfretaining barbed suture for parenchymal repair during laparoscopic partial nephrectomy; initial clinical experience. BJU Int. 2012;109(6): 906-909.
27. Erdem S, Tefik T, Mammadov A, et al. The use of self-retaining barbed suture for inner layer renorrhaphy significantly reduces warm ischemia time in laparoscopic partial nephrectomy: outcomes of a matched-pair analysis. J Endourol. 2013;27(4):452-458.

28. Zondervan PJ, Gozen AS, Opondo D, Rassweiler JJ, de la Rosette JJ, Laguna MP. Partial nephrectomy: is there an advantage of the selfretaining barbed suture in the perioperative period? A matched casecontrol comparison. World J Urol. 2012;30(5):659-664.

29. Wright JL, Porter JR. Laparoscopic partial nephrectomy: comparison of transperitoneal and retroperitoneal approaches. J Urol. 2005;174(3): 841-845.

30. Ng CS, Gill IS, Ramani AP, et al. Transperitoneal versus retroperitoneal laparoscopic partial nephrectomy: patient selection and perioperative outcomes. J Urol. 2005;174(3):846-849.

31. Fan X, Xu K, Lin T, et al. Comparison of transperitoneal and retroperitoneal laparoscopic nephrectomy for renal cell carcinoma: a systematic review and meta-analysis. BJU Int. 2013;111(4):611-621.

32. Brown JA, Hubosky SG, Gomella LG, Strup SE. Hand assisted laparoscopic partial nephrectomy for peripheral and central lesions: a review of 30 consecutive cases. J Urol. 2004;171(4):1443-1446.

33. Engel JD, Williams SB. Unclamped hand-assisted laparoscopic partial nephrectomy for predominantly endophytic renal tumors. Urol $J$. 2013;10(1):767-773.

34. Gohil R, Ahmed K, Kooiman G, Khan MS, Dasgupta P, Challacombe B. Current status of robot-assisted partial nephrectomy. BJU Int. 2012;110(11):1602-1606.

35. Haseebuddin M, Benway BM, Cabello JM, Bhayani SB. Robot-assisted partial nephrectomy: evaluation of learning curve for an experienced renal surgeon. $J$ Endourol. 2010;24(1):57-61.

36. Mottrie A, De Naeyer G, Schatteman P, Carpentier P, Sangalli M, Ficarra V. Impact of the learning curve on perioperative outcomes in patients who underwent robotic partial nephrectomy for parenchymal renal tumours. Eur Urol. 2010;58(1):127-132.

37. Dulabon LM, Kaouk JH, Haber GP, et al. Multi-institutional analysis of robotic partial nephrectomy for hilar versus nonhilar lesions in 446 consecutive cases. Eur Urol. 2011;59(3):325-330.

38. Petros F, Sukumar S, Haber GP, et al. Multi-institutional analysis of robotassisted partial nephrectomy for renal tumors $>4 \mathrm{~cm}$ versus $</=4 \mathrm{~cm}$ in 445 consecutive patients. $J$ Endourol. 2012;26(6):642-646.

39. Hughes-Hallett A, Patki P, Patel N, Barber NJ, Sullivan M, Thilagarajah R. Robot-assisted partial nephrectomy: a comparison of the transperitoneal and retroperitoneal approaches. J Endourol. 2013;27(7):869-874.

40. Aron M, Canes D, Desai MM, Haber GP, Kaouk JH, Gill IS. Transumbilical single-port laparoscopic partial nephrectomy. BJU Int. 2009;103(4):516-521.

41. Stein RJ, White WM, Goel RK, Irwin BH, Haber GP, Kaouk JH. Robotic laparoendoscopic single-site surgery using GelPort as the access platform. Eur Urol. 2010;57(1):132-136.

42. Komninos C, Shin TY, Tuliao P, et al. R-LESS partial nephrectomy trifecta outcome is inferior to multiport robotic partial nephrectomy: comparative analysis. Eur Urol. Epub November 11, 2013.

43. Patard JJ, Shvarts O, Lam JS, et al. Safety and efficacy of partial nephrectomy for all $\mathrm{T} 1$ tumors based on an international multicenter experience. J Urol. 2004;171(6 Pt 1):2181-2185, quiz 2435.

44. Fergany AF, Hafez KS, Novick AC. Long-term results of nephron sparing surgery for localized renal cell carcinoma: 10-year followup. J Urol. 2000;163(2):442-445.

45. Huang WC, Levey AS, Serio AM, et al. Chronic kidney disease after nephrectomy in patients with renal cortical tumours: a retrospective cohort study. Lancet Oncol. 2006;7(9):735-740.

46. Gill IS, Kavoussi LR, Lane BR, et al. Comparison of 1,800 laparoscopic and open partial nephrectomies for single renal tumors. $J$ Urol. 2007;178(1):41-46.

47. Lee S, Oh J, Hong SK, Lee SE, Byun SS. Open versus robot-assisted partial nephrectomy: effect on clinical outcome. J Endourol. 2011;25(7): $1181-1185$. 
48. Springer C, Hoda MR, Fajkovic H, et al. Laparoscopic vs open partial nephrectomy for $\mathrm{T} 1$ renal tumours: evaluation of long-term oncological and functional outcomes in 340 patients. BJU Int. 2013;111(2):281-288.

49. Khalifeh A, Autorino R, Eyraud R, et al. Three-year oncologic and renal functional outcomes after robot-assisted partial nephrectomy. Eur Urol. 2013;64(5):744-750.

50. Sorbellini M, Kattan MW, Snyder ME, Hakimi AA, Sarasohn DM, Russo P. Prognostic nomogram for renal insufficiency after radical or partial nephrectomy. J Urol. 2006;176(2):472-476; discussion 476.

51. Thompson RH, Lane BR, Lohse CM, et al. Renal function after partial nephrectomy: effect of warm ischemia relative to quantity and quality of preserved kidney. Urology. 2012;79(2):356-360.

52. Fergany AF, Saad IR, Woo L, Novick AC. Open partial nephrectomy for tumor in a solitary kidney: experience with 400 cases. J Urol. 2006;175(5):1630-1633; discussion 1633.

53. Lane BR, Russo P, Uzzo RG, et al. Comparison of cold and warm ischemia during partial nephrectomy in 660 solitary kidneys reveals predominant role of nonmodifiable factors in determining ultimate renal function. J Urol. 2011;185(2):421-427.

54. Patel AR, Eggener SE. Warm ischemia less than 30 minutes is not necessarily safe during partial nephrectomy: every minute matters. Urol Oncol. 2011;29(6):826-828.

55. Gill IS, Abreu SC, Desai MM, et al. Laparoscopic ice slush renal hypothermia for partial nephrectomy: the initial experience. $J$ Urol. 2003;170(1):52-56.

56. Janetschek G, Abdelmaksoud A, Bagheri F, Al-Zahrani H, Leeb K, Gschwendtner M. Laparoscopic partial nephrectomy in cold ischemia: renal artery perfusion. $J$ Urol. 2004;171(1):68-71.

57. Landman J, Venkatesh R, Lee D, et al. Renal hypothermia achieved by retrograde endoscopic cold saline perfusion: technique and initial clinical application. Urology. 2003;61(5):1023-1025.

58. Abe T, Sazawa A, Harabayashi T, et al. Renal hypothermia with ice slush in laparoscopic partial nephrectomy: the outcome of renal function. J Endourol. 2012;26(11):1483-1488.

59. Marley CS, Siegrist T, Kurta J, et al. Cold intravascular organ perfusion for renal hypothermia during laparoscopic partial nephrectomy. J Urol. 2011;185(6):2191-2195.

60. Arai Y, Kaiho Y, Saito H, et al. Renal hypothermia using ice-cold saline for retroperitoneal laparoscopic partial nephrectomy: evaluation of split renal function with technetium-99m-dimercaptosuccinic acid renal scintigraphy. Urology. 2011;77(4):814-818.

61. Schoeppler GM, Klippstein E, Hell J, et al. Prolonged cold ischemia time for laparoscopic partial nephrectomy with a new cooling material: Freka-Gelice - a comparison of four cooling methods. J Endourol. 2010;24(7):1151-1154.

62. Nguyen MM, Gill IS. Halving ischemia time during laparoscopic partial nephrectomy. J Urol. 2008;179(2):627-632; discussion 632.

63. Bollens R, Rosenblatt A, Espinoza BP, et al. Laparoscopic partial nephrectomy with "on-demand" clamping reduces warm ischemia time. Eur Urol. 2007;52(3):804-809.

64. Eisenberg MS, Patil MB, Thangathurai D, Gill IS. Innovations in laparoscopic and robotic partial nephrectomy: a novel 'zero ischemia' technique. Curr Opin Urol. 2011;21(2):93-98.

65. Simone G, Papalia R, Guaglianone S, Forestiere E, Gallucci M. Preoperative superselective transarterial embolization in laparoscopic partial nephrectomy: technique, oncologic, and functional outcomes. J Endourol. 2009;23(9):1473-1478.

66. Lane BR, Gill IS, Fergany AF, Larson BT, Campbell SC. Limited warm ischemia during elective partial nephrectomy has only a marginal impact on renal functional outcomes. $J$ Urol. 2011;185(5):1598-1603.

67. Thompson RH, Lane BR, Lohse CM, et al. Every minute counts when the renal hilum is clamped during partial nephrectomy. Eur Urol. 2010;58(3):340-345.
68. Smith GL, Kenney PA, Lee Y, Libertino JA. Non-clamped partial nephrectomy: techniques and surgical outcomes. BJU Int. 2011;107(7): 1054-1058.

69. Wszolek MF, Kenney PA, Lee Y, Libertino JA. Comparison of hilar clamping and non-hilar clamping partial nephrectomy for tumours involving a solitary kidney. BJU Int. 2011;107(12):1886-1892.

70. Shao P, Qin C, Yin C, et al. Laparoscopic partial nephrectomy with segmental renal artery clamping: technique and clinical outcomes. Eur Urol. 2011;59(5):849-855.

71. Abreu AL, Gill IS, Desai MM. Zero-ischaemia robotic partial nephrectomy (RPN) for hilar tumours. BJU Int. 2011;108(6 Pt 2): 948-954.

72. Ng CK, Gill IS, Patil MB, et al. Anatomic renal artery branch microdissection to facilitate zero-ischemia partial nephrectomy. Eur Urol. 2012;61(1):67-74.

73. Gill IS, Patil MB, Abreu AL, et al. Zero ischemia anatomical partial nephrectomy: a novel approach. J Urol. 2012;187(3):807-814.

74. Verhoest G, Manunta A, Bensalah K, et al. Laparoscopic partial nephrectomy with clamping of the renal parenchyma: initial experience. Eur Urol. 2007;52(5):1340-1346.

75. Simon J, Bartsch G Jr, Finter F, Hautmann R, de Petriconi R. Laparoscopic partial nephrectomy with selective control of the renal parenchyma: initial experience with a novel laparoscopic clamp. BJU Int. 2009;103(6):805-808.

76. Parekh DJ, Weinberg JM, Ercole B, et al. Tolerance of the human kidney to isolated controlled ischemia. J Am Soc Nephrol. 2013;24(3): 506-517.

77. Lane BR, Campbell SC, Gill IS. 10-year oncologic outcomes after laparoscopic and open partial nephrectomy. J Urol. 2013;190(1):44-49.

78. Gupta GN, Boris R, Chung P, Linehan WM, Pinto PA, Bratslavsky G. Robot-assisted laparoscopic partial nephrectomy for tumors greater than $4 \mathrm{~cm}$ and high nephrometry score: feasibility, renal functional, and oncological outcomes with minimum 1 year follow-up. Urol Oncol. 2013;31(1):51-56.

79. Benway BM, Bhayani SB, Rogers CG, et al. Robot assisted partial nephrectomy versus laparoscopic partial nephrectomy for renal tumors: a multi-institutional analysis of perioperative outcomes. J Urol. 2009;182(3):866-872.

80. Yossepowitch O, Thompson RH, Leibovich BC, et al. Positive surgical margins at partial nephrectomy: predictors and oncological outcomes. J Urol. 2008;179(6):2158-2163.

81. Permpongkosol S, Colombo JR Jr, Gill IS, Kavoussi LR. Positive surgical parenchymal margin after laparoscopic partial nephrectomy for renal cell carcinoma: oncological outcomes. J Urol. 2006;176(6 Pt 1): 2401-2404

82. Khalifeh A, Kaouk JH, Bhayani S, et al. Positive surgical margins in robot-assisted partial nephrectomy: a multi-institutional analysis of oncologic outcomes (leave no tumor behind). J Urol. 2013;190(5): 1674-1679.

83. Ukimura O, Gill IS. Imaging-assisted endoscopic surgery: Cleveland Clinic experience. $J$ Endourol. 2008;22(4):803-810.

84. Ukimura O, Nakamoto M, Gill IS. Three-dimensional reconstruction of renovascular-tumor anatomy to facilitate zero-ischemia partial nephrectomy. Eur Urol. 2012;61(1):211-217.

85. Su LM, Vagvolgyi BP, Agarwal R, Reiley CE, Taylor RH, Hager GD. Augmented reality during robot-assisted laparoscopic partial nephrectomy: toward real-time 3D-CT to stereoscopic video registration. Urology. 2009;73(4):896-900.

86. Hawks JA, Kunowski J, Platt SR. In vivo demonstration of surgical task assistance using miniature robots. IEEE Trans Biomed Eng. 2012;59(10):2866-2873.

87. Morgan M, Olweny EO, Cadeddu JA. LESS and NOTES instrumentation: future. Curr Opin Urol. 2014;24(1):58-65. 
Open Access Surgery

\section{Publish your work in this journal}

Open Access Surgery is an international, peer-reviewed, open access journal that focuses on all aspects of surgical procedures and interventions. Patient care around the peri-operative period and patient outcomes post surgery are key topics. All grades of surgery from minor cosmetic interventions to major surgical procedures are covered. Novel techniques

and the utilization of new instruments and materials, including implants and prostheses that optimize outcomes constitute major areas of interest. The manuscript management system is completely online and includes a very quick and fair peer-review system. Visit http://www.dovepress.com/ testimonials.php to read real quotes from published authors. 